Aksaray University
Journal of Science and Engineering
e-ISSN: 2587-1277
http://dergipark.gov.tr/asujse
http://asujse.aksaray.edu.tr

Research Article

\title{
Analysis of the Effect of MAG Welding Parameters on Microstructure and Mechanical Properties of TRIP 800 Steels with Finite Elements
}

\author{
Mehmet Cakmakkaya*
}

Department of Automotive Engineering, Afyon Kocatepe University, 03100 Afyonkarahisar, Turkey

\begin{tabular}{|c|c|c|c|}
\hline -Received Date:Aug 20, 2019 & -Revised Date:Mar 09, 2020 & -Accepted Date:May 11, 2020 & -Published Online: Jun 24, 2020 \\
\hline
\end{tabular}

\begin{abstract}
In this study, MAG welding method was used. $2 \mathrm{~mm}$ thick TRIP 800 steel sheets are used in different welding parameters. Microstructures of welded joints were analyzed by taking OM (optical microscope) images from the main metal areas of the welding zone, HAZ (the region under the influence of heat). Depending on the welding parameters, (welding current: 40-50-60 Ampere, and welding speed: $5-7.5 \mathrm{~mm} / \mathrm{sn}$ ), ferritic, HAZ and martensitic phase regions were determined in microstructures in the main metal, HAZ and welding regions, respectively. The strengths of the welded connections were measured using the tensile test. Welding wire speed is chosen to obtain high penetration and ideal width welding seams. The strength of the welded bond using these parameters is determined as $1266 \mathrm{MPa}$ as the highest value. It was determined that grain growth and martensitic phase transformations occur in fusion regions and result in brittle fracture. The Fusion zone and other regions were analyzed with finite elements.
\end{abstract}

\section{Keywords}

Mechanical properties, TRIP steels, MAG welding, OM

\section{INTRODUCTION}

Today Advanced High Strength Steel (AHSS) new generation steel types are developed for the production of hybrid and autonomous vehicles because of their high safety and durability [1]. The TRIP steels are retained austenite embedded in a primary matrix of ferrite. In addition to a minimum of five volume percent of retained austenite, hard phases such as martensite and

${ }^{*}$ Corresponding Author: Mehmet Cakmakkaya, cakmakkaya1964@gmail.com 
bainite are present in varying amounts. TRIP steels typically require the use of an isothermal hold at an intermediate temperature, which produces some bainite. The higher silicon and carbon content of TRIP steels also result in significant volume fractions of retained austenite in the final microstructure One of them is (TRIP) Steels whose plasticity is increased by conversion [2-4]. These steels, the newest type of AHSS Steels, focus their attention on high strength and ductility, marvelous formability and production processes where weight savings are sought [5-6]. Automotive manufacturers carry out many studies on vehicles to improve safety, fuel consumption performance and reduce carbon emissions. These improvements increase the need for many vehicle structures. It is also important to design and manufacture these requirements to be durable and safe in static, impact and variable load situations [7- 8]. It is widely used especially in the manufacture of impact damping and beam support components in automotive production. As a member of the sophisticated high strength steel group, TRIP steels are used in a wide range of areas due to their high plasticity as well as high strength [910]. In industrial applications, electrical arc welding methods, gas-protected arc welding methods, electrical resistance welding, high-energy welding methods are frequently used in combination of various metallic materials, especially steel. As in automotive manufacturing, welding methods with and without melting are used to produce components consisting of many components. One of the most important methods of fusion welding is MAG welding technique [11]. Literature studies show that a wide scale studies on the spot resistance welding of trip steels used in automotive manufacturing industry exist and the weldability of TRIP steels by laser welding method is also studied along with studies on the plasma arc welding. In this study, it is aimed to investigate the MAG welding capability of TRIP Steels. In this context, the mechanical properties of the joint and the phase transformations in microstructure of the TRIP 800 steel sheet steel pair are studied by using MAG welding method. The heat input, which is effective on the mechanical properties and microstructure, is analyzed with finite elements. Typical problem areas of interest include structural analysis, heat transfer, fluid flow, mass transport, and electromagnetic potential. The method approximates the unknown function over the domain. To solve the problem, it subdivides a large system into smaller, simpler parts that are called finite elements [12].

$$
\begin{aligned}
& {\left[K_{t}\right]\{T\}=\{\mathrm{Q}\}} \\
& {\left[K_{s}\right]\left\{\mathrm{Q}_{s}\right\}=\left\{F_{s}\right\}}
\end{aligned}
$$

Where $\mathrm{Q}$ is the heat input, $\mathrm{T}$ is the temperature, $\mathrm{K}_{\mathrm{t}}$ is the conductivity of matrix, $\mathrm{F}_{\mathrm{s}}$ is the force, $\mathrm{Q}_{\mathrm{s}}$ displacement and $\mathrm{K}_{\mathrm{s}}$ are coefficient for strengthening the matrix. A similar finite method formulation can be used for heat transfer as seen in Eq. (1) and structural problems showed in 
Eq. (2), due similarities described previously and the finite element method division of the volume control whereas the elements maintain the properties from their origin [12]. The purpose of this study is to analyze the welding temperature distribution, which is formed depending on the welding parameters, after finishing joining of TRIP 800 steel using MAG welding

\section{MATERIALS AND METHODS}

In this study, TRIP 800 steel welded with MAG welding is tried to determine the welding temperature distribution by finite element method. General purpose finite element software ANSYS is used for this purpose. To obtain the global temperature history that occurs during the welding process, a first nonlinear temporary thermal analysis is performed. A stress analysis is then developed with the temperatures obtained from the thermal analysis used as a load on the stress model. The scope of this study is limited only to predict the temperature distribution occurring in butt and fillet welded panel structures and temperature profiles are presented shown in Fig. 5. A TRIP 800 steel base metal plate of dimensions 300x50x2 mm has been prepared according to AWS D1.1/1 standard (American Welding Society, 2004) as shown in Fig. 1. The chemical composition and mechanical properties of TRIP 800 steel used in the study are given in Table 1 and Table 2.

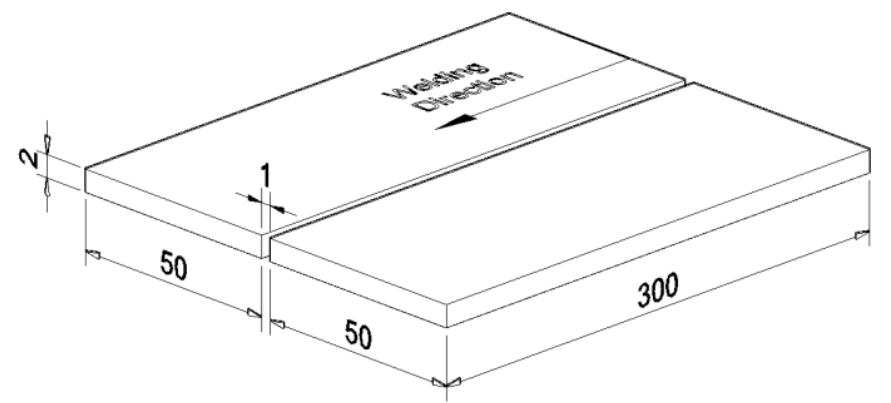

Figure 1. Welding base plate (American Welding Society, 2004)

Microhardness distributions have been analyzed using a SHIMADZU HMV Microhardness tester by applying a load of $100 \mathrm{~g}$. Specimens for the tensile test were taken from the middle of the joint and were cut using a laser cutting machine where the dimensions were according to the ASTM E8 standard, as shown in Fig. 2. 

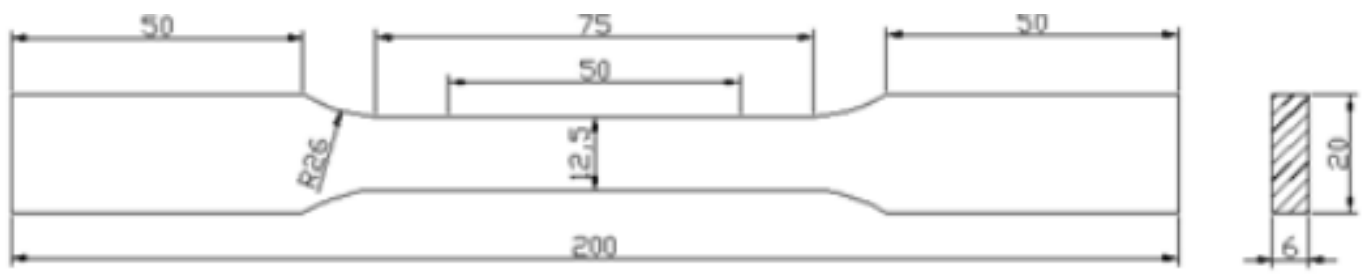

Figure 2. The planimetric view of tensile test specimen (unit mm) (American Society for Testing and Materials)

The amount of energy that is put into a weld during the arc welding process, the "heat input", is a critical parameter that must be controlled to ensure consistent weld quality. There are several ways of calculating the energy put into a weld. The most common approach to calculating the heat for non-wave form-controlled welding is to use the welding current, voltage and travel speed are listed in Table 3. An American system for this is given in ASME IX and various AWS standards, and a European system is given in EN ISO 1011-1 and PD ISO/TR 18491(American Welding Society, 2004).

Table 1. Chemical composition of TRIP 800 steel (\% weight.) [11]

\begin{tabular}{ccccccccc}
\hline $\mathbf{C}$ & $\mathbf{M n}$ & $\mathbf{C r}$ & $\mathbf{N i}$ & $\mathbf{S i}$ & $\mathbf{V}$ & $\mathbf{A l}$ & $\mathbf{N b}$ & $\mathbf{F e}$ \\
\hline 0.193 & 2.13 & 0.338 & 0.020 & 0.297 & 0.007 & 0.58 & 0.022 & 96.3 \\
\hline
\end{tabular}

Table 2. Mechanical properties of TRIP 800 steel [11]

\begin{tabular}{cccc}
\hline Material & $\begin{array}{c}\text { Yield stress } \\
(\mathbf{M P a})\end{array}$ & $\begin{array}{c}\text { Tensile stress } \\
(\mathbf{M P a})\end{array}$ & $\begin{array}{c}\text { Strain } \\
\mathbf{\%}\end{array}$ \\
\hline TRIP 800 & 435 & 825 & 24.00 \\
\hline
\end{tabular}

Table 3. Welding parameter and Head input welding EN ISO 1011-1 and PD ISO/TR 18491

\begin{tabular}{cccccc}
\hline $\begin{array}{c}\text { Test } \\
\text { No }\end{array}$ & $\begin{array}{c}\text { Current } \\
\text { (Amp) }\end{array}$ & $\begin{array}{c}\text { Gas flow rate } \\
\text { (lt/min.) }\end{array}$ & $\begin{array}{c}\text { Voltage } \\
\text { (Volt) }\end{array}$ & $\begin{array}{c}\text { Travel speed } \\
(\mathbf{m m} / \mathbf{s e c} \text { ) }\end{array}$ & $\begin{array}{c}\text { Heat input } \\
\text { (kJ/inch) }\end{array}$ \\
\hline 1 & & & & 5 & 768 \\
2 & 40 & & & 7.5 & 512 \\
3 & & \multirow{2}{*}{5} & 40 & 5 & 960 \\
4 & 50 & & & 7.5 & 640 \\
5 & & & 5 & 7.5 & 1152 \\
6 & 60 & & & & 768 \\
\hline
\end{tabular}

\section{RESULTS AND DISCUSSION}

\subsection{Microstructure and Hardness Analysis}

Table 4 shows results for tensile strength, welding seam width, penetration depth, welding zone porosity, elongation and fracture mode of the samples, respectively. The maximum tensile 
strength of $1266 \mathrm{MPa}$ was determined from Test 5 and the minimum tensile strength of 449 MPa from Test 3. In either test result, however, it was seen ductile fracture and high penetration.

Table 4. Results for effect of the welding parameter

\begin{tabular}{lllllll}
\hline $\begin{array}{c}\text { Test } \\
\text { No }\end{array}$ & $\begin{array}{c}\text { Welding } \\
\text { seam } \\
\text { width } \\
(\mathbf{m m})\end{array}$ & $\begin{array}{c}\text { Penetration } \\
\text { depth } \\
(\mathbf{m m})\end{array}$ & $\begin{array}{c}\text { Welding } \\
\text { zone } \\
\text { porosity }\end{array}$ & $\begin{array}{c}\text { Tensile } \\
\text { strength } \\
(\mathbf{M P a})\end{array}$ & $\begin{array}{c}\text { Elongation } \\
(\mathbf{\%})\end{array}$ & $\begin{array}{c}\text { Brittle } \\
\text { /Ductile } \\
\text { Fracture }\end{array}$ \\
\hline 1 & 4.087 & 0.596 & & 694 & 3.28 & Brittle \\
2 & 3.915 & 0.582 & & 549 & 2.44 & Brittle \\
3 & 4.089 & 0.766 & & 449 & 6.56 & Ductile \\
4 & 3.998 & 0.653 & None & 618 & 3.87 & Brittle \\
5 & 5.363 & 0.936 & & 1266 & 9.61 & Ductile \\
6 & 3.452 & 0.482 & & 499 & 2.92 & Brittle \\
\hline
\end{tabular}

The welding penetration and the HAZ in MAG weld on a fine- grained Type TRIP 800 steel is shown in Fig. 3. The fusion boundary is indicated by the arrows. In the HAZ, thermal cycle result in a significant grain orientation in an order of magnitude larger than those in the base metal. A more dramatic change in microstructure occurs in the HAZ of a TRIP 800 steel, as shown in Fig. 3b. The base metal of TRIP 800 steel consists of a mixture of ferrite and perlite [13]. The HAZ adjacent to the fusion boundary exhibits large grain size and a microstructure consisting of a mixture of martensite and bainite. In the as-welded condition, this microstructure would exhibit high hardness and would generally require a tempering heat treatment to restore ductility and toughness properties.

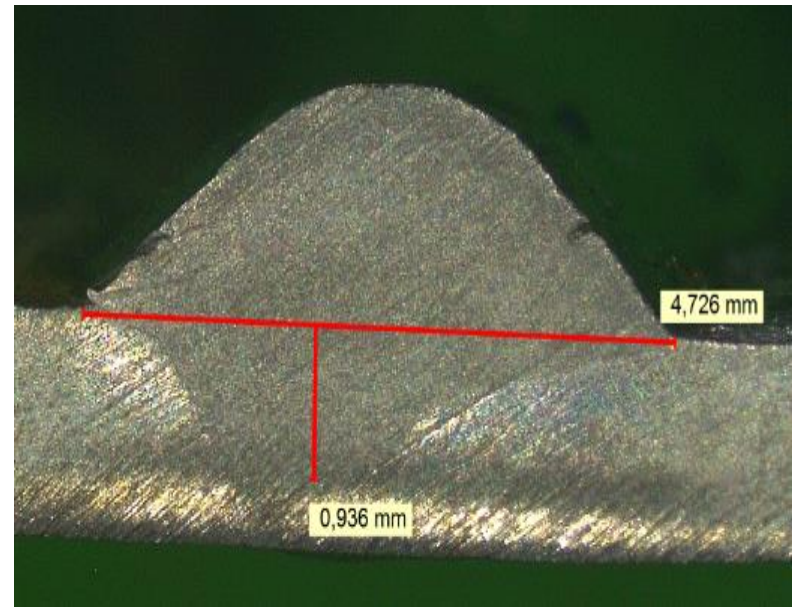

(a)

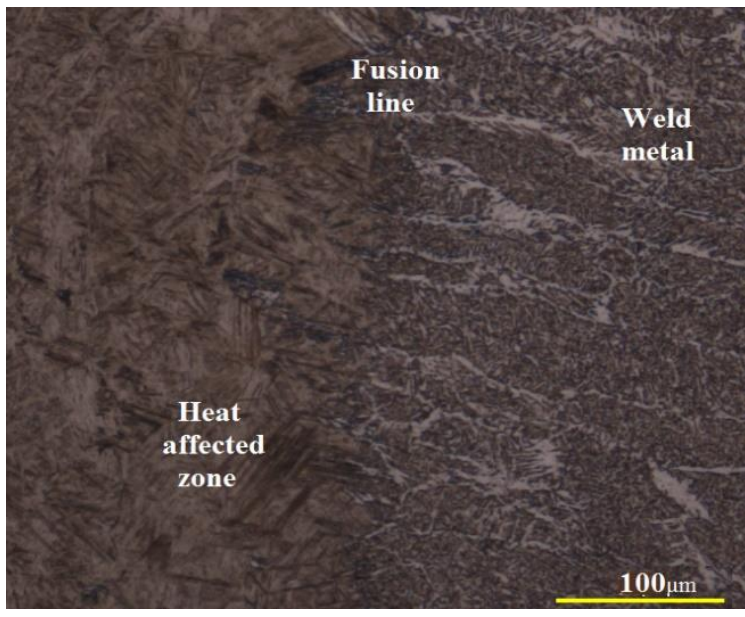

(b)

Figure 3. (a) Penetration macrostructure and (b) weld zone microstructures in TRIP 800 steel 
The chemical composition plays a major role in the joint of TRIP steels. Compositional variations have a great impact on the microstructure and mechanical properties of the joint, and will influence two key factors: the first one is related to the thermodynamic nature of the system, which governs the solidification path, and the second one is the phenomenon derived from the heat and mass-transfer process, making welding a process which provides a metastable microstructure [14].

Microhardness distributions have been analyzed using a SHIMADZU HMV Microhardness tester by applying a load of $100 \mathrm{~g}$. The microhardness test has been carried out at the surface of seams on the centerline of the weld pool, heat affected zones as border of the seam and work pieces, as HAZ of samples. As a result, at the transition zone of the weld seams i.e. the HAZ, the hardness is in the maximum level as it, compared to the base metal, experiences rapid cooling rate (see Figs. 4a, b, c). Lower heat input produces steeper thermal gradients and severe thermal straining. It was expected that by increasing total heat input to the target and reducing the cooling rate and the temperature gradient, the hardness would decrease with the increasing heat input [15].

Nevertheless, in this study, at low current and high welding speed, the heat input was at a minimum value and high cooling rates, and therefore the hardness values might be higher than those expected from other parameters. However, at higher current and lower welding speeds, higher heat input, higher hardness values were obtained because of the larger seam width. The larger seam width affected the cooling and solidification rates [16]. According to the hardness distribution graph in Fig. 4, the average hardness of TRIP 800 steel sheet main alloy consisting of bainite and residual austenite phases in the ferrite matrix was found to be $270 \mathrm{HV} 0.1$. The hardness of the section under the influence of heat varies significantly as it progresses from the base metal to the melting band. The main metal hardness of the butt-welded TRIP steel is related to the phase transformation. Increased hardness (HV) in the weld melting zone can be attributed to martensite phase transformation from austenite in this zone in Fig. 4. The fusion zone of the MAG-welded TRIP 800 steel consisting of martensitic structure exhibited high hardness (600 $650 \mathrm{Hv})$. The hardness value in the region affected by the critical heat is knitted in the region containing approximately $(400 \mathrm{Hv})$, the hardness drop (300 Hv) and the partially tempered martensite. 


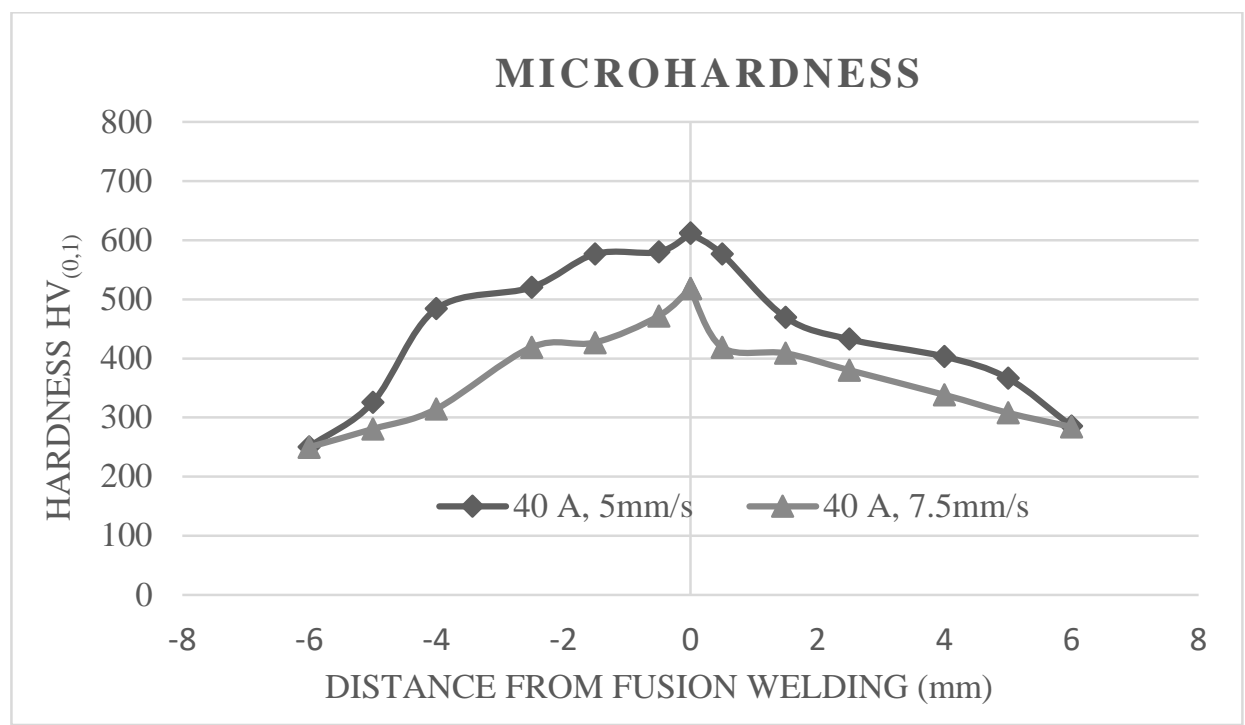

(a)

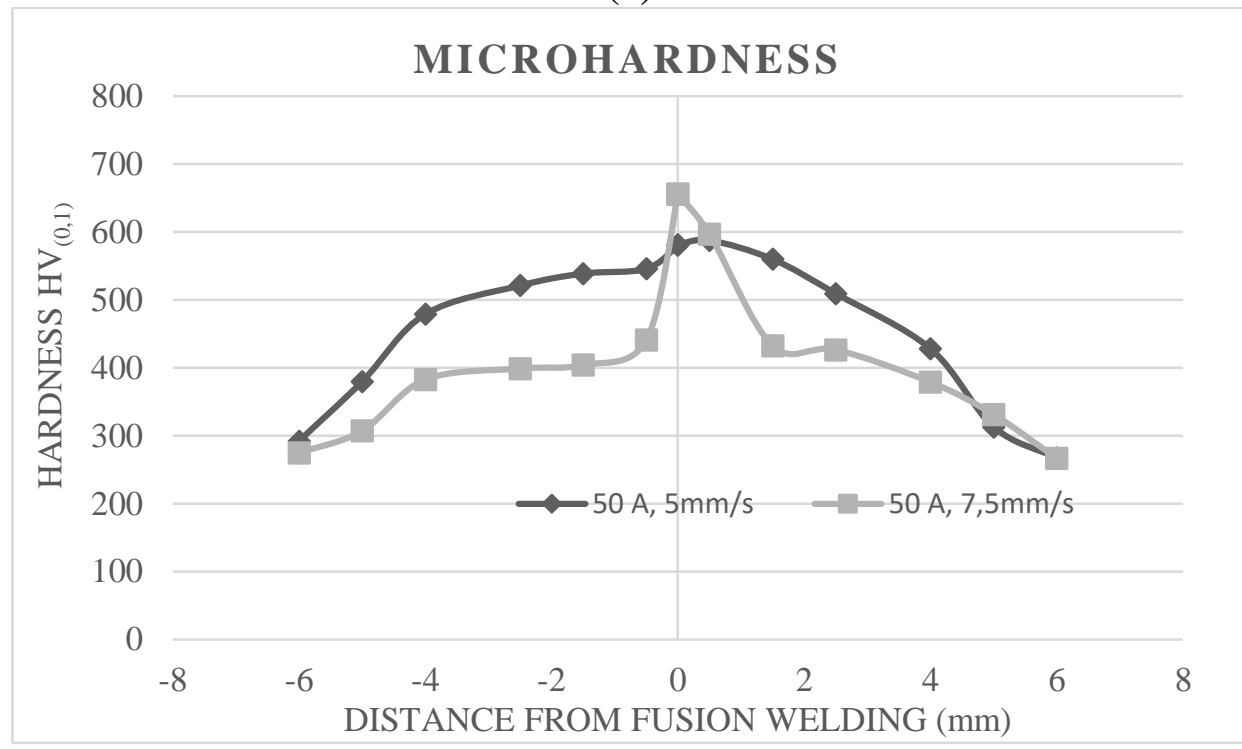

(b)

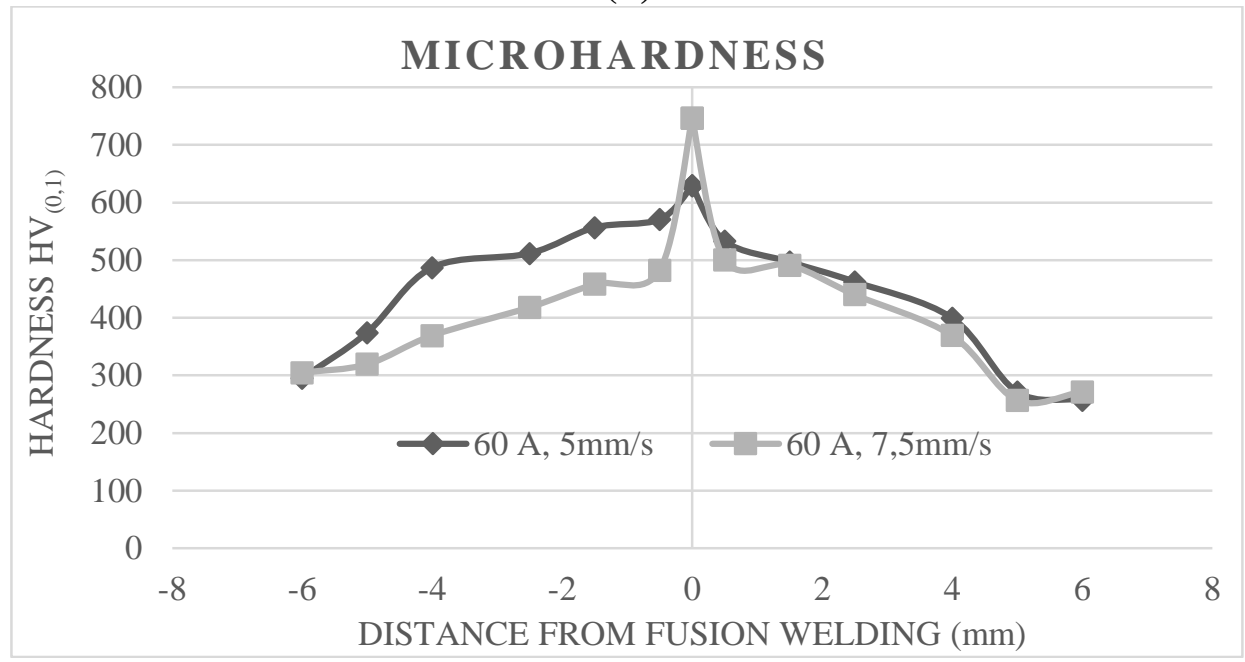

(c)

Figure 4. Micro-hardness distribution of the welding zone at different current and travel speed (a, b, c) 


\subsection{FEM Analysis Depending on the Welding Parameters}

Examination of a welded joint reveals distinct microstructural regions. The fusion zone represents region of a weld zone where there are complete melting and resolidification during the welding process. The HAZ, though not melted, is affected by the heat from the joining process. Beyond the HAZ is the unaffected base metal. These zones can be clearly seen in Fig. 3. The fusion zone is normally very distinct from the surrounding HAZ and base metal when samples are prepared metallographically. In weld where the filler metal is of a different composition from the base metal, three regions theoretically exist [17-19]. The shape of welding zone is determined by a combination of material physical properties, process parameters, and heat flow conditions. Elliptical pools are usually associated with high input, low travel speed, and 3-D head flow conditions. Materials with high thermal conductivity, such as aluminum and copper, from elliptical weld pools over a wide range of conditions. Teardrop pool shapes are most favored when travel speeds are rapid, thermal conductivity is low, and heat flow is 2-D. [20-21].

In this study, MAG welding method was used. $2 \mathrm{~mm}$ thick TRIP 800 steel sheets are used in different welding parameters. For the welding travel speed of $5 \mathrm{mms}^{-1}$ a rapid increase in temperature in the beginning of weld process goes from room temperature to around $77,7^{\circ} \mathrm{C}$ within 2 seconds and then to around $792,7^{\circ} \mathrm{C}$ in 10 seconds was observed. Afterwards, the temperature distribution tends to be stable with a maximum value of around $792,6{ }^{\circ} \mathrm{C}$ in 20 seconds. But, the welding travel speed of $7,5 \mathrm{mms}^{-1}$ causes a rapid increase in temperature in the beginning of weld process from room temperature to around $135,4^{\circ} \mathrm{C}$ within 2 seconds and then to around $744,1^{\circ} \mathrm{C}$ in 6,5 seconds. Afterwards, the temperature distribution tends to be stable with a maximum value of around $738,8^{\circ} \mathrm{C}$ in 13,5 seconds was observed. The analysis also revealed that the cooling occurs at a very slow rate as compared to the heating process MAG welding. These results can be clearly seen in Figs. 6 and 7. For the period of fusion welding, the interface between the base metal and the heat source leads to the rapid heating and melting and the strong flow of molten metal. In the weld pool, the circulation of this molten metal is driven by resistance; the shallow tension gradient, jet impingement, or friction; and, when the electric current is used, electromagnetic forces. The resulting heat transfer and fluid flow affect the transient temperature distribution in the base material, the shape, and size of the weld pool, and solidification behaviour. In all welding, only a fraction of the energy dissipated by the heat source is actually absorbed by the base metal. In the weld pool, heat is transported by means of convection and conduction [22]. 
After the removal of heat source, the maximum temperature region expands which shows that the temperature tends to distribute itself evenly. However, the overall maximum value of temperature in the zone decreases with time. The coordinate system $(\mathrm{x}, \mathrm{y}, \mathrm{z})$ is shown in Fig. 5. Its origin coincides with the centre of the heat source at the surface of the workpiece. The heat source trips at a constant speed, $\mathrm{U}$, in the same direction as the $\mathrm{x}$-axis while the workpiece remains stationary. Mathematically, this is equivalent to the case in which the heat source remains stationary while the workpiece travels at a constant speed, $\mathrm{U}$, in the $\mathrm{x}$-direction [22].

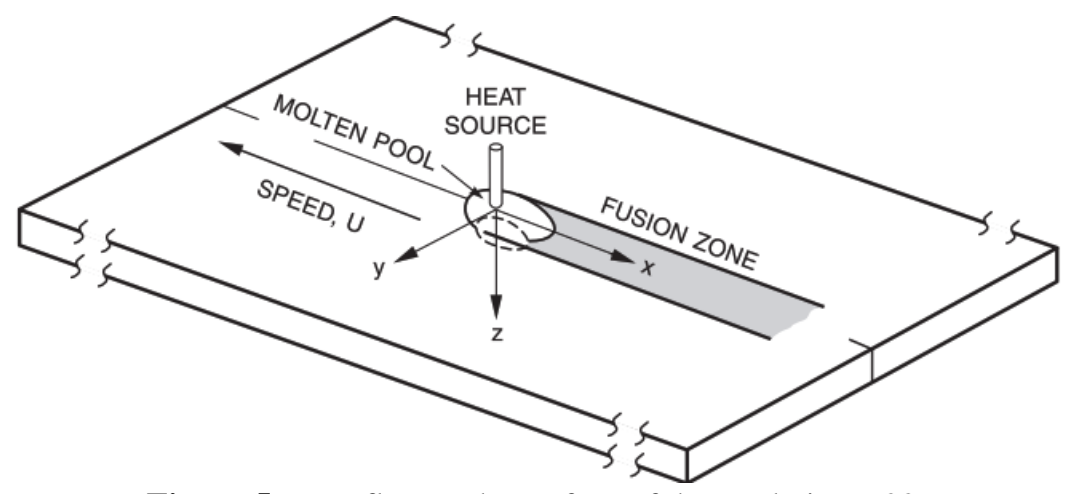

Figure 5. Heat flow at the surface of the workpiece [22]

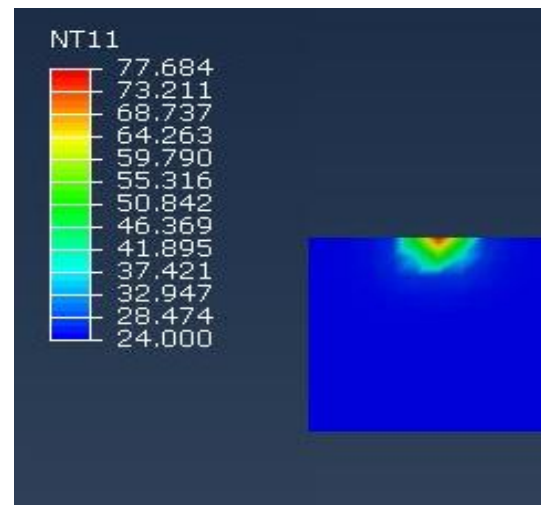

(a) $2 \mathrm{mms}^{-1}$

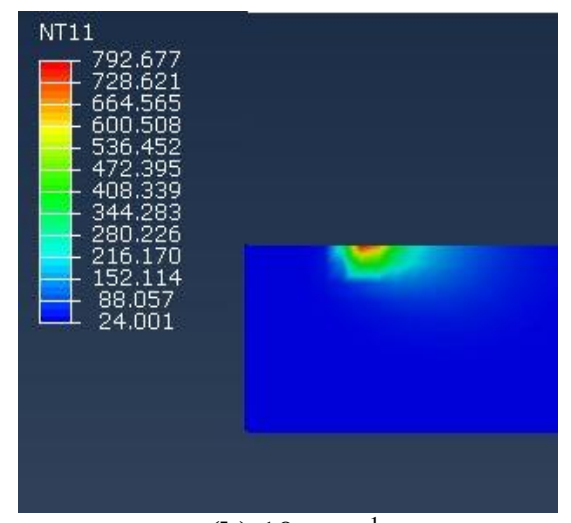

(b) $10 \mathrm{mms}^{-1}$

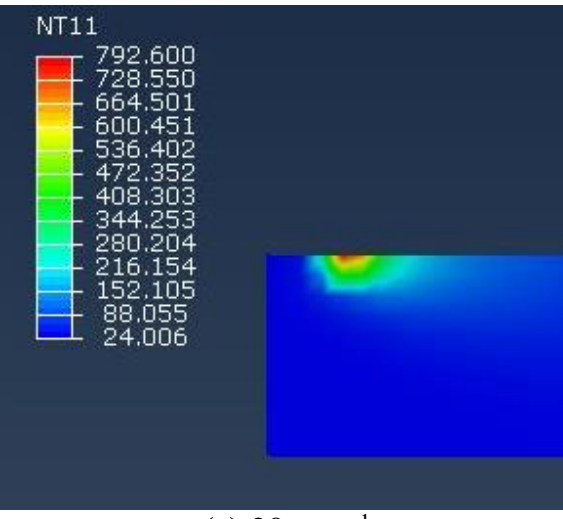

(c) $20 \mathrm{mms}^{-1}$

Figure 6. Temperature distribution during welding process at different times for different travel speeds

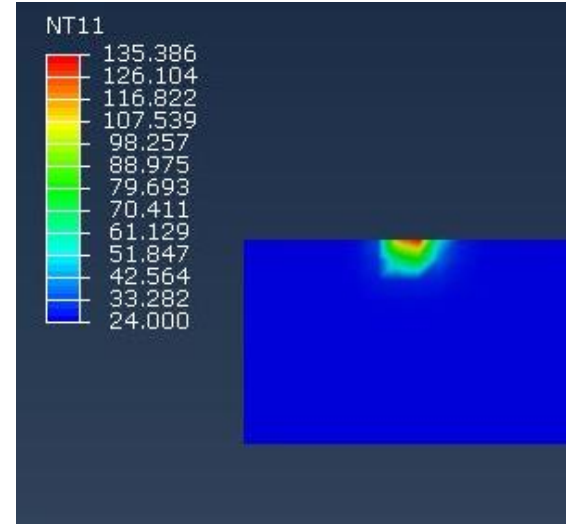

(a) $2 \mathrm{mms}^{-1}$

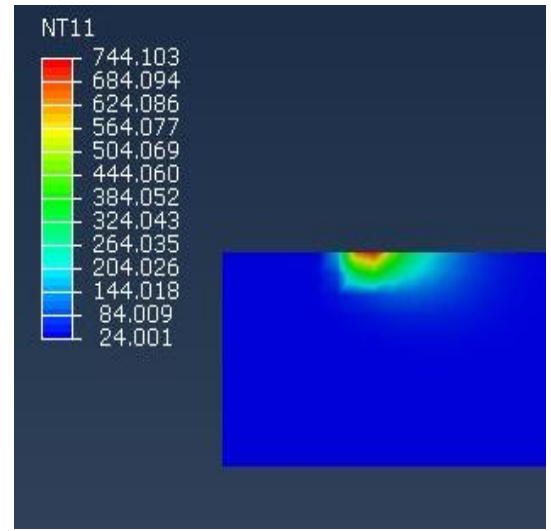

(b) $6.5 \mathrm{mms}^{-1}$

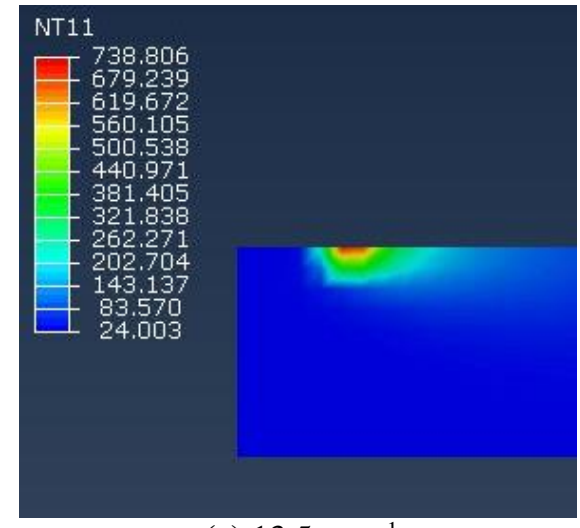

(c) $13.5 \mathrm{mms}^{-1}$

Figure 7. Temperature distribution during welding process at different times for different wire feed rate 


\section{CONCLUSIONS}

- As a result of the test, the maximum bending strength of the test specimens was found to be $825 \mathrm{MPa}$ on Average and elongation is $24 \%$.

- HAZ hardness were found in the range of $370-450 \mathrm{HV}_{0.1}$ Depending on the temperature reached in HAZ and the waiting time at this temperature, rapid cooling after welding occurs due to the nature of the fusion welding method. For this reason, it is expected that the hardness of the HAZ will vary depending on the structural transformation. Microstructure results also support this.

- The highest penetration value in the butt-welded joint was found in the sample 5 as $0.936 \mathrm{~mm}$. The average tensile strength of this weld was determined as $1266 \mathrm{MPa}$. The average elongation $(\%)$ of the test specimen was $9.61 \%$, and failed with a ductile mode.

- The average hardness of TRIP 800 steel sheet material consisting of bainite and residual austenite phases in the ferrite matrix was found to be $270 \mathrm{HV}_{0.1}$. The hardness of the part of the joint under the influence of heat varies significantly as it progresses towards the melting zone starting from the base material. Hardness varies between $370 \mathrm{HV}_{0.1}$ and $450 \mathrm{HV}_{0.1}$ in the partially transformed part of ITAB, while it ranges between $500 \mathrm{HV}_{0.1}$ in the so-called fine-grained part of ITAB. In the region of the joint, called weld metal, the hardness ranges from $580 \mathrm{HV}_{0.1}$ to $640 \mathrm{HV}_{0.1}$.

- The microstructure of the main metal formed after welding of TRIP 800 steel is composed of ferrite matrix and gives a dispersion of bainite and residual austenite. The structure formed in the weld metal exhibits a largely columnar-grained structure and the martensite phase appears to accompany them.

- According to the results of finite element analysis, heat dissipation in the structure was determined varied with high speed and low speed values. Here, deeper and wider heat fields are formed at low speed values and vice versa.

\section{REFERENCES}

[1] J.T.J. Burd, Material Substitution in Electric Vehicle Manufacturing: Comparing Advanced High Strength Steel and Aluminum, Master of Science in Technology and Policy at the Massachusetts Institute of Technology, June (2019).

[2] T. K. Pal, and K. Chattopadhyay, Resistance spot weldability and high cycle fatigue behavior of martensitic (M190) steel sheet, Fatigue \& Fracture of Engineering Materials and Structures, 34 (2010) 46-52.

[3] DK. Matlock, E. De. Moor, PJ. Gibbs, International Iron and Steel Institute Committee on Automotive Applications, Advanced High Strength Steel (AHSS) Application Guidelines, (2012) 112. 
[4] H. Ding, D. Song, Z. Tang, and P. Yang, Strain hardening behavior of a TRIP/TWIP steel with 18.8\% Mn, Material Science and Engineering A, 528 (2011) 868- 873.

[5] S. Toros, TRIP800 Çeliğinin şekillendirme Kabiliyetinin İncelenmesi ve Modellenmesi, Niğde Üniversitesi Fen Bilimleri Enstitüsü, Doktora Tezi, p. 244 (2013).

[6] E. A. M. Mendonça, E. M. Braga, A. S. A. Ferreira, R. R. Maciel, T. S. Cabral, and J. T. B. Lopes, Computer Analysis of the GMAW and GMAW-CW welding Thermal cycles, Thermal Engineering, $14: 2(\mathbf{2 0 1 5}) 37-42$.

[7] L. Mujicaa, S. Weber, H. Pinto, C. Thomye, F. Vollertsene, Microstructure and mechanical properties of laser-welded joints of TWIP and TRIP steels, Materials Science and Engineering A 527 (2010) 2071-2078.

[8] R. Youmin, Z. Guojun, H. Yu, Study on deformation and residual stress of laser welding 316L Tjoint using 3D/shell finite element analysis and experiment verification, Int. J. Adv. Manuf. Technol., 89 (2017) 2077-2085.

[9] Š. Vrtiel and M. Behúlová, Analysis of temperature and stress-strain fields during laser beam welding of a TRIP steel, IOP Conf. Series: Materials Science and Engineering 726 (2020) 012002.

[10] A. Govik, L. Nilsson, R. Moshfegh, Finite element simulation of the manufacturing process chain of a sheet metal assembly, Journal of Materials Processing Technology, 212:1 (2012) 1453-1462.

[11] P. Zhang, J. Xie, Y. Wang, and J. Chen, Effects of welding parameters on mechanical properties and microstructure of resistance spot welded DP600 joints, Science and Technology of Welding and Joining, 16:1 (2011) 567-574.

[12] M. Lisunova, Y.P. Mamunya, N. Lebovka, A. Melezhyk, Percolation behaviour of ultrahigh molecular weight polyethylene/multi-walled carbon nanotubes composites, European Polymer Journal 43:3 (2007) 949-958.

[13] S.A. Awad, E.M. Khalaf, Evaluation of the photostabilizing efficiency of polyvinyl alcohol-zinc chloride composites, Journal of Thermoplastic Composite Materials, 33:1 (2020) 69-84.

[14] W. R. Calado, Welding Handbook (9th Ed.) Vol. 1, Welding Science and Technology (2001).

[15] S. Keller, M. Kimchi and P. J. Mooney, Advanced High-Strenght Steels Aplication Guidelines Version 6.0. WorldAutoSteel, April (2017).

[16] N. Fonstein, TRIP Steels. In: Advanced High Strength Sheet Steels (Cham: Springer) (2015).

[17] N. Lun, D.C. Saha, A. Macwan, H. Pan, L. Wang, F. Goodwin, Y. Zhou, Microstructure and mechanical properties of fibre laser welded medium manganese TRIP steel, Materials\&Design 131 (2017) $450-459$.

[18] J. Ronda and G. J. Oliver, Consistent thermo-mechano-metallurgical model of welded steel with unified approach to derivation of phase evolution laws and transformation-induced plasticity Comput, Methods Appl. Mech. Eng. 189 (2000)361-417.

[19] L. Kučerová and M. Bystrianský, Comparison of thermo-mechanical treatment of C-Mn-Si-Nb and C-Mn-Si-Al-Nb TRIP steels, Procedia Eng. 207 (2017) 1856-1861.

[20] C. S. Wu, G. Wang, Y. M. Zhang, A new heat source model for keyhole plasma arc welding in FEM analysis of the temperature profile, Weld. J., 85 (2006) 284-291.

[21] P. Podešva, Application of the ANSYS software for the design of welding parameters for laser welding of high-strength steels (Diploma Thesis) Slovak University of Technology in Bratislava (MTF SUT) (2019).

[22] L. Cynthia, J. A. O. Brien, Welding Handbook Welding Science and Technology, Ninth Edition Volume 1 (2001). 